lesions, which can be troublesome and very chronic, ${ }^{15}$ R. A. Cawson $^{16}$ has recommended sucking pellets of betamethasone 17-valerate. Since many cases of both types of lichen planus are mild, corticosteroids should be reserved for patients suffering appreciable symptoms that cannot be relieved by simple methods.

\section{Control of Rabies}

The case of canine rabies reported in Britain last week must raise the question whether the quarantine imposed on imported dogs and cats is long enough. In fact the question might well be asked, Can any reasonable period of quarantine be certain to exclude rabies ? If it cannot, the import of animals capable of bringing the disease into the country should be altogether prohibited.

This exceedingly dangerous disease is of virtually worldwide distribution. In recent years it has spread throughout the wild animals of Europe to a remarkable extent. Britain, like Australia, New Zealand, and some other islands, remains one of the few places free of it, a happy condition for which we have to thank our island situation and the rigorous application of a sensible law designed to isolate an animal until the incubation period of the disease is completed. Though the disease can attack many species of mammals and also birds, human infections are generally acquired from dogs and cats, especially the former. But in Central and South America the main vectors of infection are vampire bats, which infect cattle, while the dog is of no importance in spreading the disease.

The incubation period in the smaller mammals is usually a few weeks, and four months is about the longest normally expected. In Great Britain from 1919 to 1969 some 77,000 dogs and felines went through the quarantine period of six months, and 29 dogs and one leopard developed rabies during the period. ${ }^{1}$ But, if experience in man is any guide, incubation may be expected to vary greatly in accordance, at least in part, with the nature and site of the injury through which the virus gained access to the nervous system. While seldom under 10 days in man and usually shorter than three months, it may extend up to one year or even to three. ${ }^{2}$ Though the incubation period is usually three to six weeks in the dog, it can rarely be a year or longer. ${ }^{1}$ When this unpredictable variability is considered in relation to the present recrudescence of the enzootic disease in Europe and other parts of the world, the need to review the quarantine regulations is clear. Vaccination of animals is held not to offer an effective safeguard.

Though cases of rabies in man have been reported in Britain in recent years, ${ }^{3-5}$ they were in people who were infected abroad. The last case of human infection contracted in this country was in $1911 .^{\circ}$ Despite perennial campaigns in the correspondence columns of newspapers, nothing whatever can justify any easing of the restrictions on the quarantine regulations, for they have given this country a freedom from a grave disease that few others enjoy.

1 Kaplan, M. M., Nature, 1969, 221, 421.

- Manson-Bahr, Sir P. H., Manson's Tropical Diseases, 16th ed. London, Baillière, Tindall and Cassell. 1966.

- Laughlin, J., and Ross, D. J. C., Lancet, 1956, $1,421$.

- Ghosh, S., British Medical fournal, 1964, 2, 167

- Ridley, A., British Medical fournal, 1965, 1, 1596.

- Boulger, L. R., Lancet, 1966, 1, 941.

\section{Sensitivity to Fluorescent Lighting}

Abnormal sensitivity of the skin to light is common, and the diagnosis is usually readily apparent from the history and distribution of lesions on it. Refined techniques can discriminate between many different types of light sensitivity. They include the use of narrow bands of the spectrum of known energy content from a monochromator ${ }^{1}$ and photopatch testing-that is, irradiation of ordinary patch tests with ultraviolet light.

When a patient is found to be sensitive to light it is first necessary to consider whether one of the many photosensitizing drugs ${ }^{2}$ is the cause. The commonest are sulphonamides and related antidiabetic drugs, thiazides, and phenothiazines, but even contraceptive pills ${ }^{3}$ and cyclamates ${ }^{4}$ used as sweeteners have on occasions been incriminated. External contact with photosensitizers must also be considered. They include chlorpromazine, to which nurses are apt to be exposed, and such topical medicaments as antihistamines. More common are reactions to antibacterial substances so frequently added to toilet soaps and whose incorporation is so seldom divulged by the manufacturers. The large outbreak due to tetrachlorsalicylanilide a few years ago has now been replaced by cases aggravated by related chemicals. ${ }^{5}$ In this type of contact reaction it has been suggested that the light alters the chemical to produce another active substance, which causes an ordinary contact dermatitis. ${ }^{6}$ Traces of these substances may be found in the skin for months afterwards and may account for some of the persistent reactions to light. ${ }^{7}$

Many cases of light sensitivity cannot be attributed to any exogenous substances nor to such endogenous photosensitizers as porphyrins. Thorough investigation of this idiopathic group has diminished its size and split it up into various smaller groups depending not only on the clinical picture but also on the wavelengths responsible. Most of such cases are provoked by the shorter wavelengths of ultraviolet light similar to those which cause normal sunburn and which are filtered off by window glass. In contrast, many of the external photosensitizers are activated by the longer wavelengths of ultraviolet light which pass through glass and for which conventional sunscreens are ineffective. It is important that this type of light should be used for photopatch testing.

Recently S. Brown, P. R. Lane, and I. A. Magnus ${ }^{8}$ have recorded five cases of light sensitivity provoked by fluorescent lighting. They showed the higher content of long ultraviolet waves from fluorescent lamps than from tungsten bulbs. No external photosensitizer was apparent, and in three of their cases the eruption was intractable. It seems probable that such reactions are by no means as rare as the few reports suggest and that the indoor worker even in winter can no longer be considered exempt from photodermatoses. It also means that the fluorescent lighting of many hospital wards may not be the best in which to nurse light-sensitive patients.

1 Magnus, I. A., British fournal of Dermatology, 1964, 76, 245.

- Kirshbaum, B. A., and Beerman, H., American fournal of the Medical Sciences, 1964, 248, 445.

s Erickson, L. R., and Peterka, E. S., fournal of the American Medical Association, 1968, 203, 980.

- Lamberg, S. I., Fournal of the American Medical Association, 1967, 201, 747

5 Osmundsen. P. E., and Broadthagen, H., British fournal of Dermatology, 1964, 77, 249.

- Willis, I., and Kligman, A. M., Fournal of Investigative Dermatology, 1968, 51, 378.

7 Willis, I., and Kligman, A. M.,. Fournal of Investigative Dermatology, 1968, 51, 385.

- Brown, S., Lane, P. R., and Magnus, I. A., British fournal of Dermato$\log y, 1969,81,420$. 